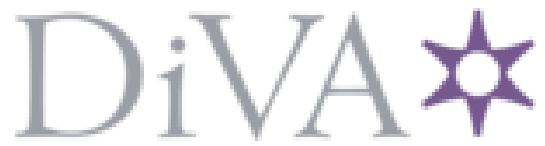

http://www.diva-portal.org

\title{
Postprint
}

This is the accepted version of a paper presented at CHI Conference on Human Factors in Computing Systems, 8-13 May 2021, Yokohama, Japan.

Citation for the original published paper:

Márquez Segura, E., Turmo Vidal, L., Waern, A., Duval, J S., Parrilla Bel, L. et al. (2021) Physical Warm-up Games: Exploring the Potential of Play and Technology Design In: CHI '21: Proceedings of the 2021 CHI Conference on Human Factors in Computing Systems, 440

https://doi.org/10.1145/3411764.3445163

N.B. When citing this work, cite the original published paper.

Permanent link to this version:

http://urn.kb.se/resolve?urn=urn:nbn:se:uu:diva- 451257 


\section{Physical Warm-up Games}

Exploring the Potential of Play and Technology Design

\section{ELENA MÁRQUEZ SEGURA}

Department of Computer Science and Engineering, Universidad Carlos III de Madrid, Spain

\section{LAIA TURMO VIDAL}

Department of Informatics and Media, Uppsala University, Sweden

\section{ANNIKA WAERN}

Department of Informatics and Media, Uppsala University, Sweden

\section{JARED DUVAL}

Department of Computational Media, University of California Santa Cruz, United States

\section{LUIS PARRILLA BEL}

Department of Informatics and Media, Uppsala University, Sweden

\section{FERRAN ALTARRIBA BERTRAN}

Social Emotional Technology Lab, University of California Santa Cruz, United States

Warm-up games are widespread practices in multiple activities across domains, yet little scholarly work can be found about their role in physical training. Here, we study potential goals and benefits of warm-up games, and explore opportunities for technology inclusion through investigating a collection of warm-up games gathered: online, from a survey of online warm-up games curated, described, and used by Physical Education teachers; and in person, from an ongoing design research work as part of a technology-supported circus training course. Further, in the context of the latter, we conducted explorative design interventions, augmenting a range of the warmup games with wearable technology. Our work surfaces major goals and benefits of warm-up games, which can be broadly classified as preparing participants physically, socially, and mentally. We also show how the inclusion of open-ended technology can support these goals and discuss broader opportunities for technology inclusion in warm-up games.

CCS CONCEPTS • Human-centered computing Interaction devices • Human-centered computing Empirical studies in $\mathrm{HCI}$

Additional Keywords and Phrases: Play, Circus, Wearables, Training Technology Probes, Warm-up Games, Playification

ACM Reference Format: 


\section{INTRODUCTION}

In physical training, technology can be employed to support training (e.g. [36,55]), to provide real-time feedback (e.g. $[8,47,50]$ ) to provide instruction (e.g. [53,61]), and to support post-training reflection of the trainee (e.g. [48]). Play design concepts and expertise are often leveraged to design interactive training activities that are entertaining and fun [45,51]which can in turn increase efficiency (e.g. [33]). Bringing together physical activity, play and technology has led to emergence of new forms of interactive, playful experiences targeting physical training, e.g. exergames [45,58], and serious games for health [11,19]. This article adds to that body of work by looking specifically at a particular subset of training practices: warm-up games. Warm-ups, including warm-up games, are activities that take place before physical training; and have been described as "procedures" [27] or "preliminary exercise(s)" [52] prior to, and in preparation for a subsequent training activity. According to The Oxford Dictionary of Sports Science \& Medicine, a warm-up typically comprises of two components: "(a) mild exercise to literally, raise tissue temperature along with stretching exercises to reduce the risk of muscle and joint injury, and (b) specific movements to rehearse the skills involved in the movement and to prepare the athlete psychologically".

Warm-up activities with a game or playful element are found in a wide range of practices and across domains [27], including sports training and physical education, but also in theatre, choir singing, teambuilding, and creative ideation. However, they are scarcely featured in academic and design works both in the domain of sports/physical education and in games and play design. While warm-up activities have a clear objective in training activities, it is unclear why games are used during warm-up. It is widely accepted that fun serves a purpose beyond skill development [27]; yet, it is not that clear what that purpose can be in the context of warm-ups, what the game and playful aspect may add, which kinds of games are most commonly used, and what are common features and goals of those games. In this article, we develop a deeper understanding of the domain of warm-up games, and investigate the potential for enriching such games through technology augmentations.

This article presents two results. Firstly, we investigate the significance of warm-up games for physical training to better understand these activities - in particular, to have a clearer understanding of their goals-and explore the opportunities they may afford for technological intervention. Following an inductive, explorative and design-oriented approach, we report on: 1) an analysis of an online survey of warm-up games created, described, and used by Physical Education (P.E.) teachers; and 2) an analysis of the warm-up games instructors used in a technology-supported circus training course. Secondly, we elicit and discuss the potential for technology augmentation in warm-up games based on our experience introducing 3 wearables into the warm-up activities in that same course. For example, technology helped make warm-ups more varied, acted as an external referee towards which participants were flexibly oriented, provided opportunities for signaling oneself and others, and supported specific movement patterns and qualities that were difficult to foster without technology.

The empirical work was done in the context of Super Trouper, a project in which we designed technology-supported training practices for children aged 9 to 12 that exhibit signs of Sensory-Based Motor Disorder (SBMD), such as issues with movement sensing and actuating. The project is run in collaboration with a professional circus and circus school, Cirkus Cirkör. While warm-ups were not the focus of the project, they were an essential training component that Cirkus Cirkör would always include in their training courses. The exploration of technology-supported warm-up games emerged as an opportunity in the context of this project.

Through our work, we contribute to the design space of technology-supported movement-based games in HCI (e.g. $[3,39,45])$ by eliciting common warm-up goals and effects, and potentials for technology augmentation. Specifically, we show broader aims and goals of warm-up games in physical training than facilitating a physical preparation: they also 
serve to prepare the trainee cognitively and socially. For each of these, we surface a more nuanced subset of sought effects. Last, we articulate a set of opportunities for technology inclusion to support these goals and effects.

\section{BACKGROUND ON WARM-UP GAMES}

Here we use the term warm-up games to denote a wide range of playful activities that are run as preparation for some kind of training exercise [27]. Typically, warm-up games are run at the beginning of a training session, but they can also be used to initiate a new training activity during a session. While this article focuses on warm-up games in the context of Physical Education (P.E.) training, they are also found in practices outside of sports and P.E. where warm-up games focus on playing with social norms and dynamics within groups, for example in theatre (e.g. improvisation) [26], or productive group work (e.g. work environments). An example is Gamestorming [20], a collection of game and play activities for creative processes. It includes various warm-up activities to unleash creativity and create a permissive atmosphere within the participating group.

In sports literature, mini-games have primarily been studied as an overarching strategy for training in lieu of specific exercises, i.e. game-based training [16]. When warm-up games are discussed in sports studies, they are predominantly seen as physical warm up exercises that offer additional benefits, such as being 'fun' and developing group cohesion [7]. This indicates that warm-up games have a wider purpose than just warming up physically.

The underlying motivations of warm-up games and playful activities are more explicit in literature on therapy. Warm-up activities including games have been explicitly documented in body-based therapies (e.g. [22,24]), and mindbased therapies (e.g. [13,46,60]). They range from children (e.g. [22,24]) to older adults (e.g. [18,44,60]). Their role in therapy overlaps with physical education and training in that they are often designed to "warm up" the body for rehabilitation (e.g. yawning and pitch gliding for Stroke Survivors in speech therapy [46]). Mirroring sports literature, we also find broader goals in therapy, e.g. to "set the scene" [44], or to provide a frame for action through familiar and clearly distinguished opening and closing activities, which supports continuity and orientation [22]. Warming up the body physically has been shown to positively affect people with dementia [60] and Alzheimer's [18] in their ability to perform cognitively demanding tasks. The insights from therapy thus indicate that warm-up games prepare participants at different levels. While these are common-sense goals, their importance is seldomly made explicit, or even mentioned in literature. Our work surfaces these goals and further inspects how they manifest in practice and are supported by warm-up games.

In HCI, warm-up games in training have recently been brought to attention (i.e. [58]). Related work in game studies are investigations into game tutorials and onboarding experiences in digital games [4]: where players are progressively introduced to the required skills for 'the real game.' Game tutorials are typically organized as minigames that allow players to practice and get familiar with the commands. In tutorials for movement-based games, e.g. exergames, this focus on learning the game controls can be combined with the goal of warming up the player's body to the following exergaming activity. For instance, the immersive Sphery Racer exergame [42], where the player controls the game through full-body functional training movements (e.g. squats, jumps), starts off with an initial activity where the player is gradually introduced to, and practices the different functional movements to play the exergame. This introductory activity also prepares the players physically, inviting them to move similarly-albeit typically at a lower level of exertion than in the game. 


\section{METHOD}

Our strategy towards exploring warm-up games builds on three sources: first, a survey of online collections of warmup games as used and reported by practitioners in Physical Education (P.E.) and training; second, a video analysis of warm-up games in the context of an ongoing circus training course; and third, an intervention in the same course, where we introduced wearable technology prototypes in warm-up games. Below, we present our methods for collecting and analyzing data from the respective sources.

\subsection{On-line Survey}

While some warm-up games are presented in the previously cited literature, they are scarce and poorly documented. An alternative source of information about the purpose and structure of warm-up games can be found in tools and documentation resources created for and by practitioners. In particular, there are a number of online websites directed towards P.E. teachers and sports trainers where a variety of warm-up games are collected and documented (often together with other training activities). We searched these kinds of sites, restricting our search to sites intended for P.E. with warm-up game collections for a target group within the rough age range of 6-11, (roughly the target group we center on in our physical training research). We excluded sites that only had a small sample of games, poor quality of documentation, and/or were directed towards other audiences (e.g. parents or trainers for adults, trainers in specific sports) making their collections less relevant for the project.

After a broadly scoped search, we selected three sites that stood out in their ambition to collect a wide variety of warm-up games and the quality of their documentation: The P.E. shed [62] contains ideas for training activities and suggestions for lesson plans targeting 5-15 years old; PhysEdGames [63] contains games used by P.E. teachers in elementary school (ages 6-13); Teaching Ideas [64], is a site with ideas for classroom activities for multiple subjects, including P.E., and targeting ages 5-11. P.E. shed [62] and PhysEdGames [63] were specifically directed towards P.E. teachers; Teaching ideas [64] was more generally directed towards primary school teachers. Taken together, the sites cover a range of ages and modes of training, and they all also allow teachers to contribute their own games. This allowed us to collect and analyze 106 game descriptions.

\subsubsection{Data Analysis}

We performed a first round of analysis extracting explicit functions and purposes, and obvious effects of the games. Whenever available, we made note of the age range, stated purposes, and anecdotal experiences of the practitioners. P.E. Shed and Teaching Ideas suggest suitable age ranges for the games, whereas this is sometimes omitted at P.E. Shed. P.E. Shed always state a goal for the exercise, which sometimes is very specific (e.g. "to coordinate our hands and feet"); this is mostly missing at the two other sites. We made note of the intended age range, equipment needed, and of the social play structure of the game (such as if the game was a tag game, a collaborative game, or a team competition game).

This first analysis was done conservatively. A game was classified as being of a particular type or having a specific intended effect, only if this was either explicitly stated in its description or could be easily inferred. For example, a stated effect was "this task is an exercise for children to work as a class - learning to be a 'team'” (Teaching Ideas). We coded it as 'teambuilding'. A particular intended effect that could be very often inferred was "increased heartrate," especially in games that required vigorous movement. This effect appears to be so common in warm-up exercises that it was seldom mentioned explicitly.

Our second analysis focused on three broader categories of intended effects that emerged in our first round of analysis: 'physical,' 'social,' and 'mental' effects. These categories also resonated with insights and learning takeaways 
from our experience working with circus instructors (reported in the subsequent section), as well as with literature on warm-up games as discussed previously. In this second round of analysis, we inspected each stated or inferred finegrained goal under the lenses of those overarching categories, checking if and how well the latter were representative. To do that, the game documentations were revisited from the perspective of the overarching categories, which allowed us to infer additional goals for some of the games. Staying with a conservative approach, we refrained from inferring social goals apart from those that were explicitly mentioned (e.g. 'teambuilding'), but we made additional notes of the social structure that the game employed. For example, we noted if a game was a solitary exercise or involved a group structure (e.g. a team-based or a tag game), and the socio-spatial layout used (e.g. the participants standing in a circle).

\subsection{Empirical Study}

The empirical study of warm-up games was done in the context of an ongoing project, Super Trouper, aiming to support and engage children aged 9-12 exhibiting signs of Sensory-Based Motor Disorder (SBMD) [14,43] in physical training, in particular in a technology-supported circus training course [36,54]. The technologies explored in this project were mostly wearables and were meant to support children's awareness of and attention to movement and posture [36]. Circus training (i.e. physical training through engaging in traditional circus disciplines, such as juggling, aerials and acrobatics, and balancing tricks [34,49]) was chosen because it aligns well with key training foci of SBMD therapies, including performance goals (such as focus, balance, and posture); and psychological goals (such as fostering motivation, engagement, and self-esteem) [9,43]. These, which are typically taken as success factors for physical training for the target group, have been shown to often emerge in playful interventions [9,43], which is why playful training was always a design goal for our project. Circus training aligns with this goal as well, as it allows children to learn something interesting and unusual, creates a sense of majestic outcome, and celebrates both failure and success [12].

We ran two courses together with three experienced circus artists, and instructors from Cirkus Cirkör [10] (PD1, woman; PD2 and PD3, men). Seven children who exhibited mild motor challenges (one 7; one 9; two 10; two 11; and one 12 years old) were recruited by our partner circus company through their usual channels, i.e. direct mail contacting their pool of contacts and announcement boards in the circus hall about a technology augmented course for children exhibiting motor issues. Each course lasted 6 weeks and featured one training session of approximately 2 hours every Saturday. All training sessions were video-recorded with two cameras capturing activities from different angles. After each class, we also conducted brief interviews with the children, and more in-depth interviews with the instructors about the session, the warm-up games and the exercises they used, and the potential for and effects of technology inclusion. These sessions also served to plan the subsequent training class. The study and data collection have obtained ethical approval from the national ethics council.

The exploration of technology-supported warm-up games emerged as an opportunity in the context of this project, and the focus of this paper. While warm-ups were not the focus of the project, they emerged as an essential aspect of training, and ones that lend themselves to technology inclusion. Early on, we noted that our instructors started each training session with one or two warm-up games. During the first sessions, we were observants (and in occasion participants) of the warm-up activities, which were organized and run by the instructors. In our post-session interviews with the instructors, they described how important these warm-ups were to prepare the children physically, but also to set a particular 'mood,' and to create a sense of cohesive and supportive training group. This resonated with literature on warm-up games, and with the three broader goals that emerged in our collection of warm-up games. 


\subsubsection{Intervention: Technology-Supported Warm-Up Games}

In the Super Trouper project, we followed a Research through Design approach [17], and together with the circus instructors, we explored the potential for technology inclusion in circus training for children with SBMD [36,54]. In particular, we worked with Training Technology Probes (TTPs): wearable pieces of technology designed to support physical training activities [36] with open-ended functionality, which augment body- and movement- related information (e.g. movement pace, body alignment) through external representations (e.g. sonified alignment). The TTPs were conceived and developed to be used and integrated during the main circus training practice, yet during the course of the project, we also explored their inclusion in the warm-up phase of training. There were many reasons behind this decision in addition to the fact that warm-up games were clearly an essential part of training. First, it would allow us to introduce the technology organically to the training session, i.e. integrated in an activity (warm-up) that they would do anyways as part of their training rather than in a specific introduction involving verbal explanations and free explorations. Also, including technology as part of the warm-up would help the children familiarize themselves to these gadgets (very much in the same way as a computer tutorial introduces new interaction affordances); and start working with key training skills they supported. Last, this presented us with the opportunity of exploring if and how technology could facilitate and add to warm-ups. This inclusion of technology in the warm-up games phase was possible without having to modify the technology due to their versatility [36,54]. Hence, they were easily included as part of warm-up games that had already been played, and new variations of them.

Three TTPs (Figure 1) were used in our warm-up game interventions. The Movement TTP (Figure 1, left) is implemented using the Circuit Playground Board. It augments movement pace by detecting changes in acceleration, and it provides visual and auditory feedback. When the wearer is still, or moves in a constant speed, the embedded LEDs in the board are green, and the device emits discrete, low frequency beeps. With acceleration, the LEDs turn to red, and the frequency increases. It is sewn onto a wrist band, and a patch that can be worn with loop-and-hook fasteners.

The Laser TTP (Figure 1, center) augments the wearers' body movement. It is implemented with an off-the-shelf laser pointer and a switch (top image), which is attached to an elastic band by means of a magnetic homemade buckle. It visualizes movement through the projection of the light into different surfaces (i.e. floor, other bodies, equipment).

The BraceLED TTP (Figure 1, right) includes an off the shelf, coin-cell powered color LED lights controlled by a remote and attached to a moldable piece of wire that acts as a bracelet.

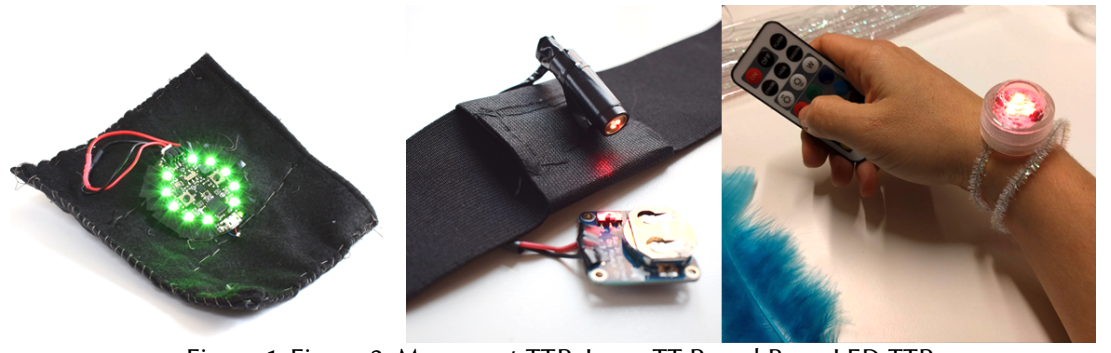

Figure 1: Figure 2. Movement TTP, Laser TT.P, and BraceLED TTP

\subsubsection{Data Analysis}

Two researchers performed an interaction analysis of the video recorded warm-ups, focusing on observable effects that the games had on the individual children and the group as a whole. Informed by both the instructors' comments, and the online survey, we focused our analysis on the physical, social, and mental effects. The interviews with instructors 
were used to complement observations, providing insights as to why certain warm-up games were selected. This way, we could code most of the observed instances of a warm-up game with their intended purpose and observable effects.

A complementary analysis of the video data was made, to also elicit play potentials [2] - that is, existing interactions that were, or had the potential of becoming playful, which emerged as the children played the warm-up games. This analysis was done by 3 researchers with an open coding approach. It resulted in a final set of 117 instances of emergent playful behaviors that we clustered into 9 codes, each representing a recurrent kind of playful engagement. This helped us understand how and why the games were fun, and how technology could contribute to this experience.

\section{OVERVIEW OF GAMES}

This section presents an overview of the collection of warm-up games resulting from the online survey and our empirical material. Our approach in both cases was inductive, explorative and design oriented, rather than evaluative - the focus was not on proving particular effects, but rather surfacing potential goals and effects. The supplementary material for this article contains an overview of the warm-up games collected in the online survey, as well as a full list and textual descriptions of the games observed in our circus training course. Below, the latter are referred to by their name and identifier used in the supplementary material.

\subsection{Games from Online Survey}

We collected 106 games total over the three sites. While some games were similar, none were identical, and therefore, we decided to treat every game description as unique in the analysis. We collected 36 games from The P.E. shed [62], 26 from PhysEdGames [63], and 45 from Teachingideas [64].

As all 3 sites include other types of games and exercises as well, we restricted our search to activities used in preparation for a training activity. In the online collection, two sites use the label 'warm-up' for physical warm-up activities (classic P.E. definition); one used the same term for a wider range of activities that also included social and cognitive warm-ups. Regarding our inclusion of activities classified as "games:" we included playful activities, some of which may not fit within strict "game" definitions (e.g. including winning conditions, rules, obstacles etc.). This reflects the broader, practical understanding and use of the concept by P.E. practitioners. We omitted games that were dedicated to specific sports (PhysEdGames features many of these), as well as activities that were too similar to ordinary training exercises to be considered playful. We omitted a few exercises that were not freely available from the websites.

We did not restrict the collection to games labelled as 'warm-up,' as the term was not used in a consistent way over the three sites. At the P.E. Shed and PhysEdGames, the 'warm-up' label is only used for games that emphasize physical warm-up, whereas Teaching Ideas classifies a much wider range of games as 'warm-up.' From the P.E. Shed, we included the categories 'Warm-up games' (13 games), 'Thinking games' (10 games), and 'Coordination games' (13 games). From PhysEdGames, we included games classified as 'Warm-up' (10 games), 'Teambuilding' (10 games) and 'Fun' (6 games). From Teaching Ideas, all of the collected activities were classified as 'Warm-up' (45 games). It deserves to be emphasized that all games were intended to be run as part of Physical Education and all required bodily movement, and as such none of them was inherently unsuitable as a warm-up exercise.

\subsubsection{Overview of the Online Games}

A compilation of the goals and social structures of the online games can be found in the supplementary material. We can note that a large number of the games were variants of tag (23 games), but various forms of team-based competitive games were also common (21 games). Purely collaborative activities were rarer (12 games), as were brawls (games where 
all compete against each other, 9 games). A very common structure included all children following the commands of a single leader, often the instructor (32 games). While it was common for games to require children to move around in the available space, using some kind of marked spatial layout was relatively rare. A large number of games used sports equipment (32 games), e.g. hula hoops or soft balls. In the next sections, the following example games will be discussed:

Traffic lights (P.E. Shed, labeled "warm up") is an example of a 'follow the leader' game. It has children pretending to be cars driving in a city. When the teacher holds up a Red, Yellow or Green cone they must act on this as if it was a traffic signal and stop or resume their movement accordingly.

Pass the hoop (from P.E. Shed, labeled 'Thinking Games'), is one of the few games that are slow-paced and collaborative. Children hold hands in a circle or a line and must pass a hula hoop from one end to the other by creeping through it without letting go of their hands. It features slow motion to move the hula hoop through the human chain.

Dancing Transitions (Teaching ideas) is a playful activity intended to work with sudden changes in motion: the suggested activity is to first dance vigorously to fast music, to next sit down and concentrate (to slow music).

Stuck in the mud (Teaching Ideas) is a variant of tag, in which those who have been tagged must freeze in place with their hands and feet spread apart, until somebody crawls under their legs to unfreeze them.

\subsection{Empirically Observed Games}

During the two technology-supported circus training courses, we observed 19 warm-up games (23 if we include game variations). Six games (9 with variations) included technology. In total, we documented 30 instances in which a warmup game was played (i.e. some of them were played multiple times).

The non-technology supported warm-up games were drawn from our instructors' repertoire or had been creatively invented by them in previous courses. The warm-up games were generally planned in advance before each training session, but the selection and order of games in a session was often adapted on the spot (e.g. due to time constraints, or to fit the needs and state of the children).

Towards the end of the second course, we researchers contributed with six warm-up games featuring technology. Most games with technology were variations of the instructors' games, and they were discussed and polished with the instructors prior to the training session. In class, game variations were primarily proposed by the instructors and involved minor tweaks (e.g. where to wear the TTPs). Other games (i.e. LaserTTP games) were initially conceived by us, and discussed with instructors to make sure they were appropriate for the children.

The complete list of games can be found in an overview table in the supplementary material. The numbers below refer to their number in that overview. Here, we include a qualitative description of a selection of games that we will

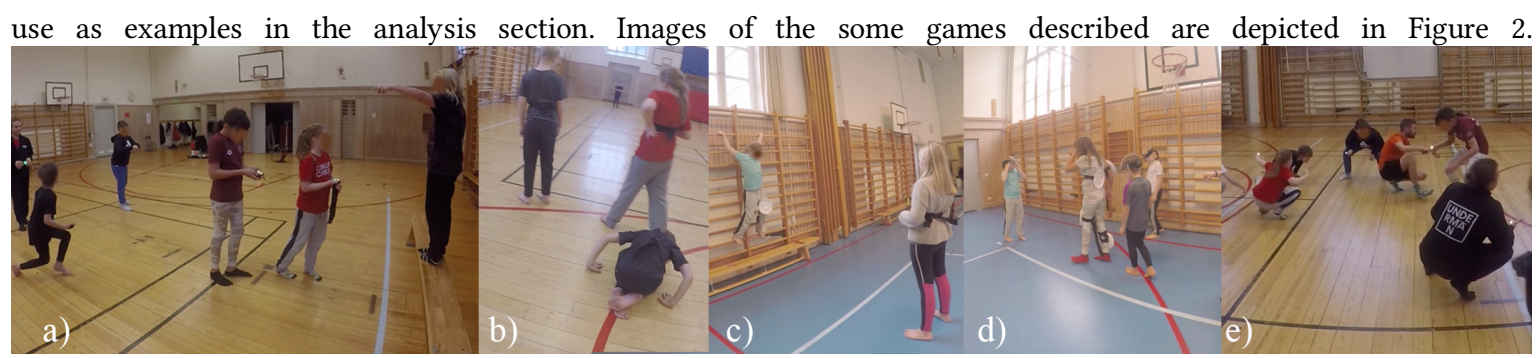

Figure 3: a) Frozen Statues with Movement TTP. b) Following with Laser. c) Laser Target. d) Human Target. e) Animal Tag with BraceLED TTP. In the Supplementary Material we provide an enlarged version to allow zooming in. 


\subsubsection{Games without Technology}

Tomtenisse (12) features a variety of gym equipment (mats, benches, vaulting poles) that are spread out throughout the room. One player is the master and guards a heap of juggling balls, placed inside a hula hoop on the floor in front of them. The rest of the players are at the other end of the space, hidden behind a big mat, which is the starting line. Their goal is to "steal" juggling balls from the master and place them into a second hula hoop, located at the starting line, without being seen by the master. The master turns their back to the other players (and the juggling balls) to count to three (using the phrase ' $1,2,3$, Tomtenisse!'), during which the other players can move and steal balls. When the count is about to finish, players need to be well hidden behind the equipment as the master turns again to face them and will call out any player that they can see. These players have to return to the starting line.

Animal Tag (10a-10d) is a tag game featuring one catcher/tagger. Both catcher and players have to move in specific ways, typically imitating animals. The movement pattern is dictated by a curator, usually the instructors.

Frozen Statues (9a-9c) features a person that is the master and that is placed far in front of a line of players. The master turns around and counts down from three. During this time, the rest of the players advance forward until the countdown is over, and the players need to freeze before the master turns around. If the master sees anyone moving, this player has to return to the starting line.

Flipping Mats (7). This is a collaborative and sometimes competitive game, featuring a group of players on top of a training mat. Their task is to collaboratively flip it without touching the floor. The game gets incrementally more difficult by adding more people per mat. The competitive variation involves competing teams on separate mats.

\subsubsection{Games with Technology}

We created game variants of Animal tag and Frozen Statues with technology. We also designed a novel technologydependent game (called Following with Laser) and several variants of it. Here we describe the technology used and briefly the games in which they were used.

Movement TTP was used in 2 games (4 variations): Frozen Statues and Animal Tag. In the technology-supported variations of Frozen Statues, players need to hold the Movement TTP and keep it green when the master turns around (i.e. indicating zero acceleration), otherwise the master can call a player out and back. In Animal Tag, the movement TTP is carried by the catcher, who needs to move keeping this TTP in green (so no acceleration, brusque movements). The rest of the players move like different animals (e.g. bear walk, lizard); the player caught needs to do a number of exercises (e.g. push-ups, crunches).

BraceLED TTP was used in Animal Tag (2 variations). In this technology-supported version, a player catches and needs to catch the rest of the players within a limited area of the space. All players but the catcher wear a BraceLED, controlled by a remote controller. A non-player game master walks around changing the lights of these bracelets to individuals. Each color is associated with a particular movement, with which the wearer needs to move.

Laser TTP was used in a new game called Following with Laser (3 variations) (1-3). In the first variation, one player wears a laser (place of their choosing), the other a plate (the target). The player with the plate moves around the room slowly. The player with the laser needs to keep the laser on the target at all times. In a second variation, one player wearing a lot of plates (targets) moves in the room. The rest of the players, wearing lasers, need to keep their lasers on a target. The third variation presents solo play: each player wears a laser wherever they want with which they follow the lines drawn on the floor of the gym. 


\section{RESULTS}

In the following sections we present the results of the analysis of both data sources (online and empirically observed games). This allows us to show how they relate to, and complement, each other. We focus on explicitly stated goals (mostly from the on-line collection) and use goals and observable effects from our empirical analysis to add more nuance.

Our online analysis substantiated three overarching principal goals of warm-up games: to prepare the trainee physically, socially, and mentally. This resonated with the warm-up game goals foregrounded by our instructors during our interviews. They pointed out that warm-up games were always present in their training classes with children. They explained their importance to prepare the children physically to the training activity to come. They also remarked the importance to socially warm them up to others, both to break the ice but also to emphasize group cohesion: "in circus a lot you train by yourself, so [warm up games are] almost the only thing you do as a group." They also mentioned they would use warm-up games to challenge children physically and mentally. All in all, they remarked on how they used warm-up games to have children "interacting, having fun, moving and challenging them in all these ways. [...] All those things can be addressed with warm-up games".

\subsection{Fun and Enjoyment}

As discussed briefly in the introduction, our scope for warm-up activities were those that bore a playful component, i.e. warm-up games. In our online survey, their description would often make a statement about a game as 'fun,' without elaborating on what made it fun. Our video analysis of the play potentials [2] yielded an understanding of how the 'fun' effect may come about.

The most common form of playful engagement was the use of performativity (26 instances). This includes, for example, making sounds to add dramatism to an action such as tagging someone. Explorative behaviors were also recurrent (16), mostly in the form of experimenting with the possibilities of the technology, the space, or one's own body (and any possible combination between those three). Several moments of joy and laughter also had to do with moments of celebration of successful completion of a task (13), both by participants and non-participants (or audiences) of the activity. Interestingly enough, we also observed the emergence of playfulness and laughter in moments of failure (12), both individual and collective. We also noted that the children enjoyed figuring out creative ways of increasing the difficulty of the warm-up activities (11): sometimes to make it harder for themselves and sometimes for others. Children also found joy in cheating (8), which led to several moments of laughter from the whole group. They also enjoyed behaving in silly ways (8): dancing and jiggling, exaggerating their movements in performative ways, and enacting silly characters. Finally, we also noted some situations in which laughter emerged as a result of a moment of intensity (4), where the intensity of the activity increased and added an element of thrill.

While our study does not allow us to link particular manifestations of fun and enjoyment to specific physical, social, and mental effects, we observed increased engagement, focus, motivation, and creativity during the warm-up games. This is consistent with previous observations of the subsequent training session whenever playful and gameful components were introduced (e.g. some children would held challenging positions longer when a gameful challenge with a TTP was introduced [36]).

\subsection{Warming up Physically}

As the Oxford Dictionary of Sports Science \& Medicine states, almost all warm-up games include an element of physical warm-up. However, this warm-up can have different focus. 


\subsubsection{Focus on exertion and keeping a specific energy level}

Aligning with the common understanding of warm-up games to prepare the trainee physically, the most common goal for the online warm-up games was increasing the heartrate (50 online games). This goal also manifested in the empirical observations, where 4 games (7 variations) offered a fast-paced, high level of exertion gameplay.

For the observed games, we could also infer related but more nuanced effects, such as in the case of the Animal Tag (10a-d) games which were specifically designed to work with strength training, and endurance. Their choice of animal determined the level of effort, which the instructors modulated as they saw fit during the training. This game was played both with and without technology. When played with the BraceLED TTP (10a-10b), the technology introduced an interesting variability and asymmetric component: instead of all moving like a same animal, each player moves according to the animal their BraceLED indicates. The leader is still in control of what animals the participants should imitate, but in this case through managing the remote control. The leader can opt for giving the same challenge for all, adapt the challenge to the individual to present them with an adequate challenge. While these games posed a challenge for the children, it was one of their favorite games, in particular with the BraceLED. An instructor reflected on this: "The kids had so much fun! [...] the game was easy to come up with, it works really well [...] they loved it so much! It's what DORI said: 'I wanna play more!' they really liked it.”

\subsubsection{Slowing Down and Working with Movement Quality}

Slow games were extremely rare in the online survey of warm-up games, an exception being Pass the hoop. This does not mean that they are scarce in practice; it is possible that they have been excluded due to the general idea that warmup games should involve an element of physical warm up. Yet, in our empirical observations we saw that it is difficult to control the pace of the children's movement without the use of some supporting technology or training tool.

In our empirical observations, we found 3 games featuring technology (6 variations) that foregrounded slowing down and focusing on movement precision and quality. This sometimes meant an increased physical and exertion challenge. For example, the game Animal Tag referred above played with the Movement TTP (10c-10d) introduced an extra exertion challenge imposed by the technology, which acted as a tattletale of brusque movements that were not allowed for the catcher player. This typically meant slower and more controlled movements, which increased the physical challenge and exertion. These games were not intended to increase exertion, but supported movement and postural exploration, and increased sensitivity and awareness, such as the whole family of Following with Laser (1-3), wherein children slowed down their usual movement pace, to control the position and direction of their laser, and hence their bodies and movements. This movement skill was very important for all, but particularly so for several children who found it particularly difficult to slow down.

\subsubsection{Open Exploration of Movements and Poses}

In the online survey, many of the game descriptions explicitly state that they are intended to train coordination or training particularly difficult movements. In total, 15 games total had coordination as (one of) their explicitly stated goals. In the empirical observations, coordination exercises were more explorative, and allowed for the exploration of a range of unusual movements. Examples of games without technology are the aforementioned Animal Tag, and the game family of Moving in the space (6b, 15-17). In the online collection, most movement coordination games tended to require higher levels of precision than what we saw in our empirical observations, but there were also some games featuring unusual and odd movements and poses, such as the 'follow the leader' games. 
This goal was quite present in games with technology, regardless of the technology, such as in Frozen Statues, Following with Laser series, and Animal Tag. In general, technology supported more intense exploration of what was possible in terms of movement and poses. Many children were observed exploring the mapping of the technology through action and inspection of the effect displayed in the technology, which in turn influenced their movements and actions. For example, one kid would hold the Movement TTP in one hand and try different balancing poses (e.g. on one leg, airplane) while checking the changes in color in the TTP. We also observed many children exploring strange and weird postures in the Animal Tag game with lights, the Following with Laser game series, and the Frozen Statues with the movement TTP. In particular, unconventional and contrived poses and movements were commonplace in Following Lines (3), a variant of Following with Laser. Many children executed contorted postures, such as bent back backwards, or on their knees, while dragging themselves on the floor. This particular game was of an aggregated type [5] (i.e. children are playing "alone, together"), and children were focused on their movements and the projected lights. Yet, they were also seen in social games, most notably in the Laser Target game which was played in pairs.

\subsubsection{Changing Movement Patterns}

Some of the observed games specifically prescribed changes in movement pace. For example, the original game (9) and many variations within the family of Frozen Statues with and without technology (e.g. 9b, 9c) invited two kinds of movements: fast during the countdown (to advance towards the master (finish line); and still when the master turns around to call out moving players back to the starting line. This type of game is relatively rare in the online survey, but a few examples exists, including a game description of a very similar game from Teaching Ideas.

In the games where technology was used to further vary the range of movements explored (see 5.1.2), it also resulted in a change of movement patterns. For example, in the Animal Tag family (10-10d), movement and pace changed at the same time, as new movements were called out. Technology intensified these changes. Most noteworthy were the changes in movement patterns, that resulted from spontaneous strategies to work with the technology. For example, when playing Animal Tag with the Movement TTP (10c, 10d) worn by the catcher player, the catchers would change their way of moving to allow them to come close and tag another player. For example, they would lower themselves before tapping on a player who was moving close to the floor. Hence, in this game variation, catcher players worked not only with different ways of moving, but also with movement planning, and control.

\subsubsection{Exploring and Practicing Specific Movements}

Forty-two games from the online survey included some form of training of specific kinds of movements and actions. For younger children, this typically involved things like running, stopping, turning, or striking specific poses. Online warm-up games working on specific movements and skills, such as throwing and catching balls, or dribbling, mostly targeted older children. This goal manifested in our empirical observations 4 games (13 variations) involved practicing specific skills such as ball handling, fine-grained, precise movements, and balance.

The Movement TTP, Laser TTP, and BraceLED TTP facilitated practicing and working with specific movements (like animal movements when playing Animal Tag game with lights 10a, 10b); movement qualities, such as precise, bound and flexible [21] movements following the lines of the gym with the laser in Following Lines with laser (3), or constant speed movements when playing Frozen Statues with the Movement TTP (9a). The latter two are not surprising, given that those TTPs were originally designed to work with those movement and training goals. Yet this points to the fact that first, these warm-up games managed to make the most of the core functions of the technology; and second, that the game design succeeded to support and engage children to work with key training goals. 


\subsubsection{Exploring and Working with the Space}

A large number of the games from the online survey involved keeping track of and moving through space (21 games), and/or keeping track of the movements of other players (11 games). In our empirical observations, this was an observable effect in 5 games (13 variations) that involved spatial exploration and working with proxemics. A clear example is Tomtenisse (12): The children have to navigate the space and keep track of the size of each object. Another example is the Following with laser family series (1-3), in which the players move together or on their own throughout the space, and use it as a resource to increase the challenge for others. By design, the space was used in the single player laser variation of Following lines (3), wherein children followed the lines on the floor. But more interestingly, children playing "it" or "the leader" in the Laser Target (1) and Human Target (2) variations spontaneously made use of gym equipment, stepping on, and climbing equipment, which forced "the followers" to imitate the leader's movement through space.

\subsection{Social: Warming-up to Others and Interacting Socially}

In the online survey, the most commonly stated social goal was Teamwork (18 games). But as most of the games were intended to be played together with the whole class, they were inherently social. This was also true in our observations: all of the observed warm-up games were played with the whole group of children - and the researchers and instructors - participating. More detailed goals are explored below.

\subsubsection{Exploring Different Modes of Social Play}

Twelve online games were strictly collaborative, such as the aforementioned game Pass the Hoop. Some observed warmup games were also collaborative, e.g.: games that required people to stand forming a circle.

Collaboration also emerges within teams during competitions, and in versions of tag where the rules allow some collaboration against the tagger. In the online survey, we found 21 examples on team competitions, and 13 examples of tag where the players could collaborate, such as the Stuck in the Mud tag game. In our empirical observations, 6 games (11 variations) built on some form of collaboration. For instance, Tomtenisse requires players to synchronize their movements and collaborate among each other to achieve their goal.

Another form of warm-up game that featured prominently in our online survey was an aggregated form of play, in which children play both individually but together: they move individually, although in the same space and in sync, following the teacher's commands, e.g. in Traffic Lights. 31 online games had this structure. Some featured elements to make the game social, e.g. through the socio-spatial arrangement of standing in a circle holding hands, or mirroring another person performing the same moves. In our observations, 6 games (15 variations) feature this form of play, such as the Animal Tag games (10a -d). One game that involved following the instructor (17) was done in silence.

It is not uncommon for warm-up games to be competitive. In addition to the team-based competitions, the online survey identified 9 games as brawls, games were all compete against all. These are typically high-paced games requiring agility and proxemics awareness. In our empirical observations, 7 games (14 variations) featured some form of competition. Most were some kind of "team against leader", as in the example of Tomtenisse. Few were team-based competitions, such as Flipping Mats (7).

In the technology-supported games, the TTPs were included in the different modes of play: in collaborative games such as Laser Target (1) and Human Target (2), from the Follow the Laser series; in aggregated types, such as Following Lines (3) (also with Laser TTP); and in competitive games such as Frozen Statues with Movement TTP (9a, 9b) and Animal Tag with Movement TTP (10c, 10d) and with the BraceLED (10a, 10b). 


\subsubsection{Exploring Different Social Roles}

Warm-up games can present different roles for different players. In the online survey, different variants of tag are the most common example. In our empirical observations, 8 games (15 variations) featured asymmetric play among players, in which one or more had a distinct role from the others. Both Tomtenisse (12) and Frozen Statues (9) identifies one child as the leader, who is placed far in front of a line of players and the other children can move only when the leader is not looking. In our observations, children favored and sought experiencing different roles, for instance: when playing the aforementioned games, children would often ask to be the leader if they had not done it before, and would step out of the role after a while to let somebody else take over.

In the technology-supported warm-up games, the social role was often associated to wearing or not wearing a TTP. In Frozen Statues (9a-c) the leader or it is the only player who is not wearing a movement TTP; the rest of the players are wearing one and by that, are bound by the same rules and share the same goal of reaching the leader first. In Animal Tag with the movement TTP (10c-d), the catcher is the only player who is wearing the device. In the variation of the same game that used the BraceLED TTP, all players except the game master wear them. The game master is not themselves participating, but in charge of the remote control changing the lights. This leads to children orienting themselves to this person in particular ways. Some sought this person out, presumably hoping to get a color change and be able to move differently; others avoided them presumably for the opposite reason. In Laser Target (1) the player wearing the plate is the leader; and the player wearing the laser is the follower. In this asymmetrical game, the item worn defines the role of each player.

Changing roles was coveted during the games. For example, many children expressed desire for taking the role of it in Frozen Statues, and policed that every single movement TTP was kept green. In turn, they wanted that TTP when playing the Animal Tag variation with that technology. Another very desired role was the game master in the variation of that game using the BraceLED TTP. Some children asked for this role enthusiastically, yet the instructors often dismissed the petition playfully. In other games, e.g. Laser Target (1), children took turns being the follower and the leader, but gravitated towards the leader role, sometimes making it complicated for the follower to keep up.

\subsubsection{Social Dynamics: Cheating, Teasing, Aiming to Win}

From the online games' description, it would seem as if they always are, or are expected to be, played according to the stated rules, with the intention of winning, when there is a win condition. This is not so clear in the observed games.

We observed that winning was important in the competitive games, both for instructors and children. Children would often tease each other when winning, e.g.: in Frozen Statues, the winning child would sometimes tease the curator through pointing and laughing at them, or screaming that they won. Instructors would often act as referees, determining what was allowed and what was cheating, and when the win condition had been reached.

A recurring strategy towards winning was cheating. Most cheats were done to 'win,' e.g. in the Animal Tag games (10a-d) where children would ignore constraints on how to move in order to be able to tag or to avoid being caught. However, sometimes an instructor would also cheat to help, by not punishing a move. This happened in Frozen Statues (9,9a-c) when the children were supposed to stay still but had struck a particularly challenging pose. We saw instances of cheating to make the game harder, e.g. the leader (a child) turning around too quickly in Tomtenisse or Frozen Statues. We also saw a couple of instances of 'cheating to get caught,' which seemed to be a way of teasing the others.

Cheats were cleverly negotiated within the group. Children and instructors would sometimes call out the cheats. But sometimes, a transgression remained uncalled, seemingly because it added to the playful atmosphere of the game. In games featuring technology, we saw instances where the technology's feedback was openly disregarded to allow for 
cheating behaviors: for example, in the variation of Frozen Statues with the movement TTP and in particularly challenging frozen poses (e.g. airplane), the instructor often "played dumb" before red flags by the technology - allowing children to continue to play. These observations illustrate how cheating presents a rich basis for communication and social interaction, and to explore and push social boundaries. From the analysis of play potentials, we can also see how these negotiations, together with the playful embracing of failure, were sources of fun.

In other games that featured technology, technology was often used as an aid to assess winning strategies. For instance, in Animal Tag with lights, Frozen Statues with the movement TTP, participants would directly look at the technology to know what movement was allowed. Children often settled discussions about potential cheating and rules by referring to the technology. For example, in the Frozen Statues variation without technology, the curator is the person deciding who they saw moving and needs to go back to the starting line. While this can be contested, the curator typically had the last say. However, the TTP in this game provided some evidence to discuss the grounds for punishment. We noted that the curator often had a stronger case to call somebody out by referring to the visual and audio cues from the technology. Yet, this variation also takes away some of the curator's authority.

\subsection{Cognitive: Getting into the Right Mindset}

In the online survey, cognitive goals were present in several games. In our empirical material, and in the interview with instructors, cognitive effects were present and actively sought after through the games.

\subsubsection{Strategic Thinking and Memory}

In the online survey, 9 games had strategic thinking as a stated goal. Most of these were team competitions. Some games focused on problem-solving and memory training, and a few (3) included a reading or math challenge. In our empirical observations, 3 games (4 variations) required of some sort of strategic thinking. The Zip-zap and the Passing balls games (5a, 6a, 6b) involved memory and focus training.

Tomtenisse was particularly interesting from this perspective. In this game, the players had to plan ahead where to move and hide, and collaboratively envision a strategy to achieve their goal of getting the balls. Since this game was popular with the children and played multiple times, we saw how they developed team-work strategies over time, e.g. move gym equipment to better hide themselves.

Some of the observed games that included technology fostered strategic thinking in relation to planning and executing movement. One example is in the game Frozen Statues, in which the children developed strategies to keep the Movement TTP in green, such as moving fast, and stopping early, with enough time before the countdown was over to allow the technology to "cool down" and display green. One child "hacked" the game by realizing that moving steadily with constant speed would allow him to keep moving during the whole time, while keeping the technology signal green. This strategy became extremely popular in subsequent rounds, even with children who usually had a hard time moving with careful, slow, and controlled movements.

\subsubsection{Fostering Concentration and Focus on Movement}

Few online games focused on fostering concentration. One of them was Dancing Transitions (Teaching Ideas), which has as its explicit goal to help transition the students to a more concentrated mode of thinking.

In our empirical observations, we observed children becoming more concentrated after playing some of the games (4, in 12 variations). Two of these were Passing Balls (6a) and Moving with Balls (9c), in which the task was to observe and mimic the instructor while keeping silent, where some level of concentration was required in exercises focused on 
performing movements accurately or focusing on certain body parts. Some games foregrounded concentrating on other senses other than sight, for instance, in Blind Sculpting (18), one player plays the sculpture and poses still in a particular pose of their choosing. The other player, blindfolded, makes use of tactile sensing to figure out this pose. Once they have it, the second player poses like the sculpture. Then they check how much they look like each other.

Several games with technology foregrounded focus and awareness on the own movement via the technology's feedback. Focus was important in the Animal Tag game to move accordingly to the rules, given the game master could remotely change one's light at any time. We noted children regularly checked up on their bracelets to make sure their movements aligned with the instructed one.

This focus intensified in Frozen Statues. Children regularly checked up on their TTP (in fact, a child barely kept her eyes off the TTP, which were held in her hands in front of her). Physical challenge came from either controlling a continuous speed movement, or well-timed movement changes to avoid being caught. Focus intensified in Following Lines (3) while exertion generally decreased. The physical challenge here came from working with movement precision and concrete body parts (where the lasers were worn).

The Following with Laser game series was particularly good at supporting children work with and focus on specific body parts, and with general bodily orientation in relation to the space, which we attributed to the augmenting capacity of the lasers projecting in space. The game Laser Target (1) allowed children to work with movement precision, synchronization and orientation, which not only was physically challenging, but required focus.

\subsubsection{Fostering Feelings of Success}

The instructors foregrounded that children achieved a sense of "success," of "having achieved something," which may impact their self-confidence and self-esteem. Instructors would often try to balance the games so all children would get the chance at feeling successful. For instance, in Tomtenisse, instructors would often help children that experienced more challenges running through the obstacles, to hide and steal the balls. Once these children had achieved this, they would cheer and encourage them. This also happened in other games (e.g. Animal Tag series), where all children were complimented and cheered on for seemingly normal tasks (e.g. avoiding getting tagged), but a special emphasis was put on those with severe challenges.

\section{DISCUSSION}

Here we reflect on the manifold goals of the warm-up games as illustrated by our online and empirical results, and discuss the opportunities for technology support for warm-up games resulting from our empirical observations.

\subsection{Physical, Social and Mental Warm-up}

We observed that warm-up games in physical training have multiple purposes, of which warming up the body is just one. Inspired by literature on warm-up activities in physical education and the goals stated by our instructors, we analyzed the role of warm-up games to also prepare participants socially and mentally for the training activity at hand. They set the tone for subsequent activities and allow the participants to work with core skills and competencies.

From the interviews with trainers, we understood that the choice of warm-up activity was dependent both on the focus of the subsequent training activity, and on the children in training. Many of the children participating in our course exhibited concentration issues, which foregrounded the importance of mental preparation. This explains why the trainers very often would include warm-up activities that required focus and concentration. 
The fact that warm-up games are used to foster social cohesion is less surprising. This goal is often explicitly mentioned in the games collected in the on-line survey, often as "teambuilding." This was also a central goal during the warm-up activities used in the course. Given that the circus training activities are mostly performed individually, the instructors found important the role of warm-up games to create an opportunity for social interaction, help the group come together and be friends with each other. Interestingly, all of the games played displayed social elements.

Last, instructors always strived for balanced warm-up phases, seeking that warm-up games complemented each other, e.g.: instructors expected some of the technology-based games (e.g. laser-related games) to bring focus and movement awareness, but also added a more physically active warm-up game "so that they don't get cold" (PD2).

\subsection{Opportunities for Technology Inclusion}

In this section, we highlight important aspects of warm-up games based on our analytical work and highlight how technology can contribute and add. We bridge these insights with knowledge in HCI, IxD, and Games and Play.

\subsubsection{Fostering Specific Movement Qualities and Movement Exploration}

Among the ordinary warm-up games without technology we observed in class, very few allowed for challenges related to moving slowly. The same was true for the games collected in the online survey. Moving slowly, with control and in a balanced way is an essential skill in training in general, and in circus training in particular. Further it was a physical skill that our target group had difficulties with, and would benefit from training. However, slow movements were difficult to foster without technical augmentation. Several of our technology-augmented warm-up games included ways to foster slow and focused movement that still were physically challenging for our participants. In a similar vein, technology was useful to support exercises that required change of pace, another skill that our instructors pointed the children needed to work with.

Technology was observed to support movement exploration by the children. Several physically and creatively explored how their actions were mapped with the technology, giving raise to unusual poses and movements, e.g.: during all the games of the Following with Laser game series. This technology potential is in consonance to other somatic works that capitalize on using technology and physical props to support and foster movement exploration (e.g. [32,37,59] for embodied design ideation processes), exemplifying that this potential manifests in warm-up gaming activities that have as a goal movement exploration.

The fact that children were apparently comfortable with exploring weird movement in pairs is consonant with previous works that has found that the playful framing of a game, together with the use of technology, support players to embrace weirdness and potential awkwardness [25,41]. Yet it is particularly noteworthy with our target group, since children with motor difficulties are often shy in terms of movement exploration and execution.

\subsubsection{Supporting Variability and Flexibility}

An important aspect of warm-up games seems to be that they are flexible and admit variations. Variations emerged spontaneously during one same circus training session, sometimes by initiative of the instructors (e.g. to adapt the game difficulty), and sometimes in dialogue between the instructors and the children. For example, cheating strategies observed in in Frozen Statues with the Movement TTP were welcomed by the whole group and were adopted as an accepted rule in the next game round.

Further, our instructors often re-used warm-up games from one circus training session to the next, they often included variations. The instructors discussed this as advantageous, as it would first provide a welcomed familiarity for 
the children, who would often refer to them after the class or prior to classes, and made request for subsequent training sessions). In game and play design, DeKoven presents familiarity as a core value of well-played games, i.e. games in which players are empowered to adapt them and make the most of the play experience, and play fully engaged and at their best [30].

Then, slight variations also introduced a component of novelty that children welcomed. We reason this allowed to maintain a playful attitude towards the game and allowed them to explore new possibilities (movement options, social roles, etc.) and stay away from an overly goal- and performance-oriented atmosphere, and rather embraced daring, trying, and failing without being a big deal.

The technology used in the warm-up games afforded children and instructors various uses during the games, but it also allowed the emergence of game variations to suit the capabilities of the players and their individual and collective needs. This is what DeKoven describes as well-played games [30]. The open-ended design of the TTPs used in our intervention, and their varied output and simple functionality, allowed trainers to suggest different uses of technology within a game and different games, and to use them to modify and adapt the games.

Diverse and contrasting output was an asset to cater for a wide variety of games, together with different and creative mappings. This could be seen with the remotely controlled lights used in Animal Tag, which was played in different weeks changing the mapping between colors and their prescribed movements. In turn, the movement TTP was used to prescribe a specific kind of movement targeted during a whole game, like in some variations of Animal Tag (10c, 10d); or different movements allowed at different moments in the game, like in Frozen Statues (9a, 9b).

The flexibility of the technology to portray different roles and support a same game concept was apparent in game variations featuring different technology. For example, Animal Tag was played with the Movement TTP (10c, 10d) and with the lights $(10 \mathrm{a}, 10 \mathrm{~b})$. This changed how the game was played and experienced. In the former, the movement of the it player was directly influenced by the technology-the TTP worn by it needed to stay green the whole time, which impacted the way this player moved and the strategies they would come up with to not trigger the technology. While the movement of it was also prescribed by the technology in one of the variations with the lights (10b), it wasn't the case in another variation (10a), in which it had to move like the person they were targeting.

Technology was often used to prescribe game rules, but they were also often negotiated on the fly. For example, in a session playing Frozen Statues, PD2 suggested that children wearing the Movement TTP had to hold a challenging position, like an airplane. This introduced an additional physical challenge, which was received well by the children.

Frequent changes on the spot related to the location where the technology was worn. Both the instructors and the children suggested and implemented such variations e.g. in the Following Lines game. Modifications like these made a noticeably impact in the experience, directing focus to different body parts, modifying the way children moved and effort involved, and ultimately made the experience easier, more challenging, or fun.

The variability and flexibility of technology use and the different array of games resonates with strands of work employing open-ended technologies for children's play (e.g. [6]) and physical training activities (e.g. [36,54,54,56]).

\subsubsection{Personal and Social Signaling}

Technology was used to signal prescribed movements and roles in the game. This information was obviously relevant for the wearer, since it directly influenced their behavior. For example, it was used to prescribe specific movements in Animal Tag with the lights (10a, 10b); or to augment and remind the wearer of their movement qualities (like in Animal Tag, 10c, 10d; or Frozen Statues with the movement TTP (9a, 9b). 
Yet, it was also important for others. It allowed them to monitor that the rules were being followed, to craft gameplay strategies, and to communicate and negotiate rules and cheats. This social signaling affordance creating a shared frame of reference is known of expressive wearables in the context of games and play [35], as well as physical training [53,56]. We see it as an asset to support all three major elements of warm-up games: physical (e.g. to know what movement to do), social (e.g. to know what others need to do and let them know what you are doing), and cognitive (e.g. to strategize). For this social affordance to manifest, it was important that the output was accessible to the wearer and the group (through lights in the BraceLED; lights and sound in the Movement TTP). This aligns with design recommendations for social wearables, such as the design premise of designing for self and others [15].

Social signaling did not only happen on account of the type of feedback or output implemented, but also as a consequence of just wearing the device, or displaying a particular output, like in Frozen Statues or the Animal Tag games. Wearing the device (in both games) or displaying a particular output (e.g. a color in Animal Tag unified the roles and/or actions of the wearers, which could potentially impact the players' sense of belonging and group cohesion, in line with previous results for moving together [23], and of wearing similar tokens or items $[1,23,35]$.

Social Signaling of particular roles and actions were also associated with status and feeling of control and power, which the children coveted. This meant wearing the technology at times (e.g. the movement TTP in Animal Tag; 10c, 10d), or not wearing it (e.g. the player it in Frozen Statues with the movement TTP (9a, 9b); or the player wearing the plates rather than the laser in the Laser Target, who leads the collective movements). It could also mean handling a controller, like in Animal Tag with the lights. This is an interesting case since this desired role implied not participating in the game (a non-player handles the controller).

\subsubsection{The external referee}

Many of the original warm-up games required that one of the children or instructors acted as a referee. While this role was generally coveted, it came with the additional social responsibility of judging your peers. We observed how they frequently oriented, and refer to the technology to make assessments, and to back up their personal assessments, and to settle discussions about potential cheats. These cases surfaced a perception of the role of the technology as an objective and external source of feedback. Previous research has shown that this role of technology as an external judge, can function as a way to lower social tension within a group; and that this holds even in cases when the technology is not entirely accurate or correct [38,39].

Yet, the technology was not always given an indisputable role. We noted that sometimes, technology was playfully considered either the supreme objective authority or an ineffectual widget, depending on the children's convenience. We see this as an asset to afford negotiation of rules. Other times, the technology was completely overridden and ignored by the player in charge. This was usually the case when the instructors played that role.

\subsection{Requirements on Technology Support}

Adding interactive technology to the warm-up games may come at a cost. From the instructors' perspective, a requisite for including technology was that it would "add something" (PD1) in terms of a training effect. During discussions before and after the training session, one of the instructors reflected on some of the potential warm-up games discussed, which seemed to only add "a playful effect" but not so much from the perspective of training. This shaped the choice of technology-supported warm-up interventions, which had to support a clear training goal.

A second requirement was that the technology would not make the activity overly complicated. For example, one of the instructors proposed a variation of a tag game in which technology would signal that players needed to stay frozen 
for several seconds. This variant was discarded due to the other trainer observing that "it's [the technology] making things a bit more complicated than they have to." (PD1) In this case, the audiovisual augmentation offered by the technology was not providing any information that the participants did not already have: "If someone is frozen, it's very clear [for others]." In general, instructors favored technology with simple functionality and a clear impact in the game.

\section{CONCLUSION}

The work reported in this article contributes to research in technology-supported movement-based games in HCI (e.g. $[3,39,45])$ through foregrounding the multiple goals and effects that warm-up games may have in physical training, highlighting important considerations of technology-supported warm-up games, and proposing a set of opportunities for technology inclusion to support warm-up games.

Regarding goals, warm-up games are commonly expected to both contribute to training, which almost always includes warming up physically, and to be 'fun,' often in contrast to the subsequent, more serious, training activity.

Our analysis shows that it also involves warming up mentally and socially in preparation to the subsequent training activity. This multifaceted potential of warm-up games opens up for considering warm-ups in their own right and exploring their use beyond a preparatory pre-training warm-up phase, i.e. using them to gamify an entire training practice. For us, studying if and how this would be suitable in our particular domain remains to be explored in future work. Yet our study yielded interesting takeaways that will likely be useful to design and research warm-up games preceding training practices, as well as training sessions comprised of warm-up games.

Based on our observations of warm-up activities in a circus training class as well as on interviews with the trainers, we understand that the selection of warm-up games is not arbitrary. It depends on the subsequent training activity and the group of participants. It is also decided holistically, considering how different warm-up games complement each other and support a well-rounded activity. Last, it is both planned in advance, and modified ad hoc depending on the needs and state of the participants.

Regarding the playful aspect of the kinds of warm-up activities studied, we argue that they led to enjoyment and fun, which was in turn essential to foster interest and drive the children's engagement. This is not surprising. Enjoyment, pleasure, and experience of fun are commonly associated to games, and sought after when playing and designing games [29]. Understandably, they are one of the most frequent psychological outcomes featured in gamification works [28] for their great potential to drive behavior, such as engagement, perseverance (not giving up when failing), and endurance (holding out for longer) in the context of therapy and physical training [38]. This potential is at the core of multiple research on gamification for training [19,31,57]. It also resonates with our observations. In our work, we observed increased focus, creativity, engagement and motivation during the warm-up games, as well as at times when playful and gameful challenges emerged during training [36,40]. Since fostering motivation and engagement are typically taken as success factors for physical training for the target group [9,43], we reason our warm-up games hold interesting training potential. However, since no comparison was included in our study (warm-up activities vs. warm-up games) our data does not allow us to draw definite conclusions related to if and how warm-up games are more effective than other warmup activities.

As for the inclusion of technology, we found that they supported the emergence of play and playfulness, which the children embraced. While the instructors also appreciated this aspect, it was clear they held additional expectations for their inclusion, which were not trivial to achieve. In additional to supporting play and playfulness; technology should also provide a clear training value, and not be too complex or cumbersome to use. Our technology-supported games aligned with these requirements. Further, and very relevant to training, they helped make warm-ups more varied, acted 
as an external referee towards which the children and instructors flexibly oriented, provided opportunities for signaling oneself and others, and supported specific movement patterns and qualities that are difficult to foster without technology.

We believe that our contribution is relevant beyond the scope of our particular application domain of training with children exhibiting SBMD. The warm-up games surveyed online extend the scope of this target group; further, it should be noted that the circus trainers use very similar warm-up games in their regular courses as well.

We plan to continue working on the play potentials uncovered, since our current analysis uncovered playful behaviors that were not tapped into through our technology designs. We plan to analyze them in more depth, and explore how to leverage them to inspire future technology designs. Further work would also be needed to disentangle how particular manifestations of playfulness, enjoyment, and fun led to specific physical, social, and mental effects.

Future work could also focus on other kinds of technology -for warm-up games, we see a potential in using the shared space for technology augmentations, e.g. using sound augmentations, smoke, and light, to make the environment more playful and fantastic; as well as different target groups and group configurations -the technology we used in our explorations was designed for individual wearers and signaling within fairly small groups.

Finally, it would also be valuable to continue the exploration of warm-up games more broadly, in different training practices. Our informal observations in other domains indicate that these effects are also relevant and sought in warmup for other physical training activities and with different target groups, like adults. However, the balance between the three different goals (physical, social and mental preparation) may be different for other domains and groups.

\section{ACKNOWLEDGMENTS}

This research is funded by the Swedish Science Council, Vetenskapsrådet, award number: 2017-04880. Our work would not be possible without our Super Trouper super heroes, the children participating in this study. Last, our deepest thanks to the amazing Cirkus Cirkör team: Oskar Löfkvist, Katarina Rosen, and Isak Arvidsson.

\section{REFERENCES}

1. Kaho Abe and Katherine Isbister. 2016. Hotaru: the lightning bug game. In Proceedings of the 2016 CHI Conference Extended Abstracts on Human Factors in Computing Systems, 277-280.

2. Ferran Altarriba Bertran, Elena Márquez Segura, Jared Duval, and Katherine Isbister. 2019. Chasing Play Potentials: Towards an Increasingly Situated and Emergent Approach to Everyday Play Design. In Proceedings of the 2019 on Designing Interactive Systems Conference (DIS '19), 1265-1277. https://doi.org/10.1145/3322276.3322325

3. David Altimira, Florian Floyd Mueller, Jenny Clarke, Gun Lee, Mark Billinghurst, and Christoph Bartneck. 2017. Enhancing Player Engagement Through Game Balancing in Digitally Augmented Physical Games. Int. J. Hum.Comput. Stud. 103, C: 35-47. https://doi.org/10.1016/j.ijhcs.2017.02.004

4. Erik Andersen, Eleanor O’Rourke, Yun-En Liu, Rich Snider, Jeff Lowdermilk, David Truong, Seth Cooper, and Zoran Popovic. 2012. The impact of tutorials on games of varying complexity. In Proceedings of the SIGCHI Conference on Human Factors in Computing Systems (CHI '12), 59-68. https://doi.org/10.1145/2207676.2207687

5. Elliott M. Avedon. 1971. The structural elements of games. In The Study of Games, Avedon and Brian SuttonSmith (eds.). Wiley, New York, NY, USA, 163-178.

6. Jon Back, Laia Turmo Vidal, Annika Waern, Susan Paget, and Eva-Lotta Sallnäs Pysander. 2018. Playing Close to Home: Interaction and Emerging Play in Outdoor Play Installations. In Proceedings of the 2018 CHI Conference on Human Factors in Computing Systems (CHI '18), 156:1-156:11. https://doi.org/10.1145/3173574.3173730

7. Carlos Martín Beristain, Paco Cascón Soriano, Asociación Pro Derechos Humanos, and Seminario de Educación para la Paz. 1995. La alternativa del juego: p.: il. Los Libros de la Catarata.

8. Dominik Bial, Thorsten Appelmann, Enrico Rukzio, and Albrecht Schmidt. 2012. Improving Cyclists Training with Tactile Feedback on Feet. In Proceedings of the 7th International Conference on Haptic and Audio Interaction Design (HAID'12), 41-50. https://doi.org/10.1007/978-3-642-32796-4_5

9. Doreit Bialer and Lucy J Miller. 2011. No longer a secret: Unique common sense strategies for children with sensory or motor challenges. Future Horizons. 
10. Tilde Björfors and Katja Lind. 2010. Inside a Circus Heart (Inuti ett Cirkushjärta). Cirkus Cirkör, Stockholm.

11. B. Bonnechère, L. Omelina, B. Jansen, M. Rooze, and S. Van Sint Jan. 2014. Balance Training Using Specially Developed Serious Games for Cerebral Palsy Children, a Feasibility Study. In Proceedings of the 8th International Conference on Pervasive Computing Technologies for Healthcare (PervasiveHealth '14), 302-304. https://doi.org/10.4108/icst.pervasivehealth.2014.255332

12. Paul Bouissac. 2012. Circus as multimodal discourse: Performance, meaning, and ritual. A\&C Black.

13. James E. Burg. 2000. Adventures in Family Therapy. Journal of Systemic Therapies 19, 3: 18-30. https://doi.org/10.1521/jsyt.2000.19.3.18

14. John Cairney, J. A. Hay, B. E. Faught, and R. Hawes. 2005. Developmental coordination disorder and overweight and obesity in children aged 9-14 y. International journal of obesity 29, 4: 369-372.

15. Ella Dagan, Elena Márquez Segura, Ferran Altarriba Bertran, Miguel Flores, Robb Mitchell, and Katherine Isbister. 2019. Design Framework for Social Wearables. In Proceedings of the 2019 on Designing Interactive Systems Conference (DIS '19), 1001-1015. https://doi.org/10.1145/3322276.3322291

16. Tim Gabbett, David Jenkins, and Bruce Abernethy. 2009. Game-based training for improving skill and physical fitness in team sport athletes. International fournal of Sports Science \& Coaching 4, 2: 273-283.

17. William Gaver. 2012. What Should We Expect from Research Through Design? In Proceedings of the SIGCHI Conference on Human Factors in Computing Systems (CHI '12), 937-946. https://doi.org/10.1145/2207676.2208538

18. Marcello Giordano, Ligia J. Dominguez, Teresa Vitrano, Massimiliano Curatolo, Anna Ferlisi, Anna Di Prima, Mario Belvedere, and Mario Barbagallo. 2010. Combination of intensive cognitive rehabilitation and donepezil therapy in Alzheimer's disease (AD). Archives of Gerontology and Geriatrics 51, 3: 245-249. https://doi.org/10.1016/j.archger.2009.11.008

19. Stefan Göbel, Sandro Hardy, Viktor Wendel, Florian Mehm, and Ralf Steinmetz. 2010. Serious Games for Health: Personalized Exergames. In Proceedings of the 18th ACM International Conference on Multimedia (MM '10), 16631666. https://doi.org/10.1145/1873951.1874316

20. Dave Gray, Sunni Brown, and James Macanufo. 2010. Gamestorming: A Playbook for Innovators, Rulebreakers, and Changemakers. O’Reilly Media, Inc.

21. Ann Hutchinson Guest. 2014. Labanotation: The System of Analyzing and Recording Movement. Routledge.

22. Kristin Hartshorn, Loren Olds, Tiffany Field, Jessie Delage, Christy Cullen, and Angelica Escalona. 2001. Creative Movement Therapy Benefits Children with Autism. Early Child Development and Care 166, 1: 1-5. https://doi.org/10.1080/0300443011660101

23. Katherine Isbister, Elena Márquez Segura, Suzanne Kirkpatrick, Xiaofeng Chen, Syed Salahuddin, Gang Cao, and Raybit Tang. 2016. Yamove! A movement synchrony game that choreographs social interaction. Human Technology: An Interdisciplinary fournal on Humans in ICT Environments. https://doi.org/10.17011/ht/urn.201605192621

24. E Jelalian, R Mehlenbeck, E E Lloyd-Richardson, V Birmaher, and R R Wing. 2006. 'Adventure therapy' combined with cognitive-behavioral treatment for overweight adolescents. International fournal of Obesity 30, 1: 31-39. https://doi.org/10.1038/sj.ijo.0803069

25. Ke Jing, Natalie Nygaard, and Joshua Tanenbaum. 2017. Magia Transformo: Designing for Mixed Reality Transformative Play. In Extended Abstracts Publication of the Annual Symposium on Computer-Human Interaction in Play, 421-429.

26. Keith Johnstone. 2012. Impro: Improvisation and the theatre. Routledge.

27. Michael Kent. 2007. The Oxford Dictionary of Sports Science \&amp; Medicine. Oxford University Press. Retrieved September 20, 2019 from https://www.oxfordreference.com/view/10.1093/acref/9780198568506.001.0001/acref9780198568506

28. Jonna Koivisto and Juho Hamari. 2019. The rise of motivational information systems: A review of gamification research. International fournal of Information Management 45: 191-210. https://doi.org/10.1016/j.ijinfomgt.2018.10.013

29. Raph Koster. 2004. A Theory of Fun for Game Design. Paraglyph Press, Scottsdale, AZ.

30. Bernard De Koven. 2013. The Well-Played Game: A Player's Philosophy. The MIT Press, Cambridge, Massachusetts.

31. Renny Lindberg, Jungryul Seo, and Teemu H. Laine. 2016. Enhancing Physical Education with Exergames and Wearable Technology. IEEE Transactions on Learning Technologies 9, 4: 328-341.

32. Lian Loke and Toni Robertson. 2013. Moving and Making Strange: An Embodied Approach to Movement-based Interaction Design. ACM Trans. Comput.-Hum. Interact. 20, 1: 7:1-7:25. https://doi.org/10.1145/2442106.2442113 
33. Martin Ludvigsen, Maiken Hillerup Fogtmann, and Kaj Grønb $\backslash$ a ek. 2010. TacTowers: An Interactive Training Equipment for Elite Athletes. In Proceedings of the 8th ACM Conference on Designing Interactive Systems (DIS '10), 412-415. https://doi.org/10.1145/1858171.1858250

34. Jill Maglio, Carol McKinstry, and others. 2008. Occupational therapy and circus: potential partners in enhancing the health and well-being of today's youth. Aust Occup Ther f55, 4: 287-90.

35. Elena Márquez Segura, James Fey, Ella Dagan, Samvid Niravbhai Jhaveri, Jared Pettitt, Miguel Flores, and Katherine Isbister. 2018. Designing Future Social Wearables with Live Action Role Play (Larp) Designers. In Proceedings of the 2018 CHI Conference on Human Factors in Computing Systems (CHI '18), 462:1-462:14. https://doi.org/10.1145/3173574.3174036

36. Elena Márquez Segura, Laia Turmo Vidal, Luis Parrilla Bel, and Annika Waern. 2019. Circus, Play and Technology Probes: Training Body Awareness and Control with Children. In Proceedings of the 2019 on Designing Interactive Systems Conference (DIS '19), 1223-1236. https://doi.org/10.1145/3322276.3322377

37. Elena Márquez Segura, Laia Turmo Vidal, Asreen Rostami, and Annika Waern. 2016. Embodied Sketching. In Proceedings of the 2016 CHI Conference on Human Factors in Computing Systems (CHI '16), 6014-6027. https://doi.org/10.1145/2858036.2858486

38. Elena Márquez Segura, Annika Waern, Luis Márquez Segura, and David López Recio. 2016. Playification: The PhySeEar Case. In Proceedings of the 2016 Annual Symposium on Computer-Human Interaction in Play (CHI PLAY '16), 376-388. https://doi.org/10.1145/2967934.2968099

39. Elena Márquez Segura, Annika Waern, Jin Moen, and Carolina Johansson. 2013. The Design Space of Body Games: Technological, Physical, and Social Design. In Proceedings of the SIGCHI Conference on Human Factors in Computing Systems (CHI '13), 3365-3374. https://doi.org/10.1145/2470654.2466461

40. Elena Márquez Segura, Annika Waern, Luis Parrilla Bel, and Laia Turmo Vidal. 2019. Super Trouper: The Playful Potential of Interactive Circus Training. In Extended Abstracts of the Annual Symposium on Computer-Human Interaction in Play Companion Extended Abstracts (CHI PLAY '19 Extended Abstracts), 511-518. https://doi.org/10.1145/3341215.3356282

41. Joe Marshall, Conor Linehan, and Adrian Hazzard. 2016. Designing brutal multiplayer video games. In Proceedings of the 2016 chi conference on human factors in computing systems, 2669-2680.

42. Anna Lisa Martin-Niedecken, Katja Rogers, Laia Turmo Vidal, Elisa D. Mekler, and Elena Márquez Segura. 2019. ExerCube vs. Personal Trainer: Evaluating a Holistic, Immersive, and Adaptive Fitness Game Setup. In Proceedings of the 2019 CHI Conference on Human Factors in Computing Systems (CHI '19), 88:1-88:15. https://doi.org/10.1145/3290605.3300318

43. Lucy J Miller, Doris A Fuller, and Janice Roetenberg. 2014. Sensational kids: Hope and help for children with sensory processing disorder (SPD). Penguin.

44. Fiona Moffatt, Caroline Mohr, and David Ames. 1995. A group therapy programme for depressed and anxious elderly inpatients. International fournal of Geriatric Psychiatry 10, 1: 37-40. https://doi.org/10.1002/gps.930100108

45. Florian `Floyd' Mueller, Martin R. Gibbs, Frank Vetere, and Darren Edge. 2017. Designing for Bodily Interplay in Social Exertion Games. ACM Trans. Comput.-Hum. Interact. 24, 3: 24:1-24:41. https://doi.org/10.1145/3064938

46. Ce Naylor and E Bower. 2005. Modified constraint-induced movement therapy for young children with hemiplegic cerebral palsy: a pilot study. Developmental Medicine \& Child Neurology 47, 6: 365-369. https://doi.org/10.1017/S0012162205000721

47. Hyung Kun Park and Woohun Lee. 2016. Motion Echo Snowboard: Enhancing Body Movement Perception in Sport via Visually Augmented Feedback. In Proceedings of the 2016 ACM Conference on Designing Interactive Systems (DIS '16), 192-203. https://doi.org/10.1145/2901790.2901797

48. Sebastiaan Pijnappel and Florian "Floyd" Mueller. 2013. Designing Interactive Technology for Skateboarding. In Proceedings of the 8th International Conference on Tangible, Embedded and Embodied Interaction (TEI '14), 141-148. https://doi.org/10.1145/2540930.2540950

49. S Sahli, S Ghroubi, H Rebai, M Chaâbane, A Yahia, D Pérennou, and MH Elleuch. 2013. The effect of circus activity training on postural control of 5-6-year-old children. Science \& Sports 28, 1: 11-16.

50. Daniel Spelmezan. 2012. An Investigation into the Use of Tactile Instructions in Snowboarding. In Proceedings of the 14th International Conference on Human-computer Interaction with Mobile Devices and Services (MobileHCI '12), 417-426. https://doi.org/10.1145/2371574.2371639

51. Jakob Tholander and Stina Nylander. 2015. Snot, Sweat, Pain, Mud, and Snow: Performance and Experience in the Use of Sports Watches. In Proceedings of the 33rd Annual ACM Conference on Human Factors in Computing Systems (CHI '15), 2913-2922. https://doi.org/10.1145/2702123.2702482 
52. Alan Tomlinson. 2016. A Dictionary of Sports Studies. Oxford University Press, Oxford, New York.

53. Laia Turmo Vidal, Elena Márquez Segura, Christopher Boyer, and Annika Waern. 2019. Enlightened Yoga: Designing an Augmented Class with Wearable Lights to Support Instruction. In Proceedings of the 2019 on Designing Interactive Systems Conference (DIS '19), 1017-1031. https://doi.org/10.1145/3322276.3322338

54. Laia Turmo Vidal, Elena Márquez Segura, Luis Parrilla Bel, and Annika Waern. 2020. Training Body Awareness and Control with Technology Probes: A Portfolio of Co-Creative Uses to Support Children with Motor Challenges. In Proceedings of the Fourteenth International Conference on Tangible, Embedded, and Embodied Interaction (TEI '20), 823-835. https://doi.org/10.1145/3374920.3375002

55. Laia Turmo Vidal, Elena Márquez Segura, and Annika Waern. 2018. Movement Correction in Instructed Fitness Training: Design Recommendations and Opportunities. In Proceedings of the 2018 Designing Interactive Systems Conference (DIS '18), 1041-1054. https://doi.org/10.1145/3196709.3196789

56. Laia Turmo Vidal, Hui Zhu, and Abraham Riego-Delgado. 2020. BodyLights: Open-Ended Augmented Feedback to Support Training Towards a Correct Exercise Execution. In Proceedings of the 2020 CHI Conference on Human Factors in Computing Systems (CHI '20), 1-14. https://doi.org/10.1145/3313831.3376268

57. Anthony Whitehead, Hannah Johnston, Nicole Nixon, and Jo Welch. 2010. Exergame effectiveness: what the numbers can tell us. In Proceedings of the 5th ACM SIGGRAPH Symposium on Video Games, 55-62.

58. Frederik Wiehr, Marko Vujic, Antonio Krüger, and Florian Daiber. 2020. The Jungle Warm-Up Run: Augmenting Athletes with Coach-Guided Dynamic Game Elements. In Proceedings of the Augmented Humans International Conference (AHs '20), 1-12. https://doi.org/10.1145/3384657.3384779

59. Danielle Wilde, Anna Vallg $\backslash a$ arda, and Oscar Tomico. 2017. Embodied Design Ideation Methods: Analysing the Power of Estrangement. In Proceedings of the 2017 CHI Conference on Human Factors in Computing Systems (CHI '17), 5158-5170. https://doi.org/10.1145/3025453.3025873

60. B. Woods, L. Thorgrimsen, A. Spector, L. Royan, and M. Orrell. 2006. Improved quality of life and cognitive stimulation therapy in dementia. Aging \& Mental Health 10, 3: 219-226. https://doi.org/10.1080/13607860500431652

61. Krystyna Zaton and Stefan Szczepan. 2014. The Impact of Immediate Verbal Feedback on the Improvement of Swimming Technique. Journal of Human Kinetics 41: 143-154. https://doi.org/10.2478/hukin-2014-0042

62. The PE Shed | Physical Education Resources and PE Games. thepeshed. Retrieved September 20, 2019 from https://www.thepeshed.com

63. PHYSEDGAMES | ...click a category above for great P.E. games! Retrieved September 20, 2019 from https://physedgames.com/

64. Teaching Ideas | Free lesson ideas, plans, activities and resources for use in the primary classroom. Retrieved September 20, 2019 from https://www.teachingideas.co.uk/ 